\title{
Uma hipótese de funcionamento psicomotor como estratégia clínica para o tratamento de bebês em intervençáo precoce ${ }^{1}$
}

\author{
Dani Laura Peruzzolo ${ }^{a}$, Ana Paula Ramos de Souza ${ }^{b}$

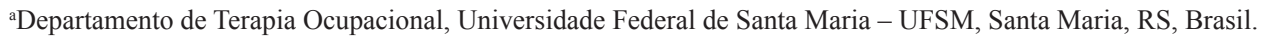

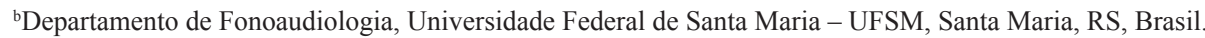

\begin{abstract}
Resumo: A melhora na qualidade do serviço e resultados de pesquisas dirigidas a bebês que apresentem transtorno em seu desenvolvimento ou risco psíquico vêm alterando o perfil do paciente em Intervenção Precoce (IP). Estas mudanças estimulam os terapeutas ocupacionais a buscar interlocuções com outros campos, como a psicomotricidade. Este estudo objetiva apresentar uma construção teórica que defende a produção de uma Hipótese de Funcionamento Psicomotor para a clínica com bebê. Reúne conceitos clássicos e atuais importantes para a IP, como função materna e paterna, e a psicomotricidade, como Esquema (EC) e Imagem corporal (IC). Defende que a irregularidade psicomotora pode ser tratada a partir de uma Hipótese de Funcionamento Psicomotor, pois considera a singularidade da interpretação dos sintomas psicomotores como um anúncio do bebê sobre si e sobre o outro, pautado pelas relações familiares em que é estimulado a fazer/ser. A IC é interpretada à luz dos conceitos de função materna e paterna, para garantir o lugar de suposição de sujeito desejado. O EC é o funcionamento motor e cognitivo que anuncia o lugar psíquico em que a IC está sendo elaborada, rompendo com o tratamento comportamental para bebês. Sob a ótica de um terapeuta ocupacional, a clínica da IP construída por meio de aportes da psicomotricidade, tomada como um fazer/ser, pode ser utilizada para o tratamento de bebês que apresentam atraso no desenvolvimento, com sintomas motores, cognitivos e psíquicos que devem ser interpretados à luz de uma Hipótese de Funcionamento Psicomotor.
\end{abstract}

Palavras-chave: Terapia Ocupacional, Desenvolvimento da Criança, Desempenho Psicomotor, Psicanálise.

\section{A psychomotor functioning hypothesis as clinical strategy for the treatment of infants in early intervention}

\begin{abstract}
The improvement in the quality of service and results of researches aimed at infants with development problems or psychic risk has begun to change the patient profile in Premature Intervention (PI). These changes have stimulated occupational therapists to seek interlocutions with other fields, such as psychomotricity. This study aims to present a theoretical approach that defends the production of a Psychomotor Functioning Hypothesis for the clinical practice with children. It gathers important classic and current concepts for the PI such as motherly and fatherly function, and in psychomotricity, such as Body Scheme (BS) and Image (BI). The study defends that psychomotor irregularity can be treated based on a Psychomotor Functioning Hypothesis, since this considers the singularity of interpretation of psychomotor symptoms as an announcement of the infant over itself and over others, lined by the family relationships that stimulated the infant to do/be. Body image is interpreted in the light of motherly and fatherly function concepts to guarantee the presumed place of wanted subject. The BS represents the motor and cognitive behavior that announces the psychic place over which the BI is elaborated, breaking through the behavioral treatment of babies. From the viewpoint of occupational therapists, the PI clinic built through contributions of psychomotricity taken as to do/be can be used for the treatment of infants who present developmental delay with motor, cognitive and psychic symptoms that must be interpreted in the light of a Psychomotor Functioning Hypothesis.
\end{abstract}

Keywords: Occupational Therapy, Child Development, Psychomotor Performance, Psychoanalysis.

\footnotetext{
Autor para correspondência: Dani Laura Peruzzolo, Departamento de Terapia Ocupacional, Universidade Federal de Santa Maria, Av. Roraima, 1000, Camobi, Prédio 26B, sala 1418, CEP 97105-900, Santa Maria, RS, Brasil, e-mail: danilaura8@gmail.com

Recebido em Jun. 5, 2016; 1ª Revisão em Out. 3, 2016; Aceito em Dez. 15, 2016.
} 


\section{Introdução}

O acompanhamento longitudinal de bebês prematuros e o uso de instrumentos de triagem para detecção de risco psíquico e risco ao desenvolvimento, no primeiro ano de vida, são exemplos de açôes que têm trazido, para tratamento em intervenção precoce, bebês sem diagnósticos de patologias. Isso tem alterado o perfil do bebê atendido, pois nem todos possuem uma síndrome ou má formação, ou encefalopatias motoras náo progressivas, que refletem em atrasos nas aquisiçóes motoras e cognitivas. Os resultados de pesquisas afirmando que a prematuridade pode provocar transtorno ao desenvolvimento, tanto motor quanto cognitivo (SASSA et al., 2011; MAGGI et al., 2014), somado ao uso de protocolos e indicadores de risco psíquico nos primeiros meses de vida do bebê (PERUZZOLO et al., 2014), coloca, em cena clínica, bebês muito novos, cujos fatores avaliados indicam descompassos nas aquisiçóes para o seu desenvolvimento (VIEIRA; LINHARES, 2011).

Destacam-se, neste âmbito, os Indicadores Clínicos de Risco ao Desenvolvimento Infantil (IRDIs) (KUPFER et al., 2010) e os sinais PREAUT (CRESPIN; PARLATO-OLIVEIRA, 2015) que, ao detectarem precocemente o risco ao desenvolvimento e risco psíquico, respectivamente, permitem um cuidado precoce de bebês que poderão desenvolver psicopatologia grave, como o transtorno do espectro do autismo-TEA (ARAÚJO; LOTUFO NETO, 2014).

Entre os sinais identificados no atraso do desenvolvimento, encontram-se os sintomas psicomotores, também associados à prematuridade (EICKMANN; MALKES; LIMA, 2012; DUAN et al., 2015) e ao risco psíquico (MURATORI, 2014).

Considerando-se o exposto, este estudo tem o objetivo de apresentar uma reflexão teórica sobre a construção de uma estratégia clínica para o tratamento em intervenção precoce, a partir de aportes psicomotores interpretados à luz $\mathrm{da}$ psicanálise, denominada Hipótese de Funcionamento Psicomotor. Foi elaborada na busca de caminhos para garantir, a cada paciente e seus familiares atendidos, uma dimensão singular, tanto na identificação do que obstaculiza o desenvolvimento quanto nas estratégias utilizadas para o tratamento. A Hipótese de Funcionamento Psicomotor foi defendida na tese da primeira autora deste artigo e é útil aos terapeutas que tomam a primeira infância como período rico para a produção de sujeitos singulares em suas condiçôes tanto estruturais quanto instrumentais, na relação com o ambiente.
O estudo constará de dois capítulos, em que o primeiro apresenta conceitos importantes que compóem a IP e a psicomotricidade, para só então apresentar, no segundo capítulo, a construção teórica da Hipótese de Funcionamento Psicomotor (HFP).

\section{Bases Teóricas para a Composição de uma Hipótese de Funcionamento Psicomotor}

Entre os conceitos que compõem a clínica em Intervenção Precoce (IP), os de "função materna" e "função paterna" apresentados por Jerusalinsky (1983), e revisitados em pesquisas atuais (SIQUEIRA; DIAS, 2011; CRESTANI et al., 2012), são especialmente potencializados quando se atribui o tratamento do bebê a uma HFP. A IP considera o campo das funçóes parentais como o espaço além dos cuidados físicos, no qual se agrega também uma função afetiva necessária para sustentar o desejo da produção dos papéis de mãe, de pai e também de filho (LEVIN, 2011).

O termo funçáo materna foi elaborado no campo freudo-lacaniano, a partir da descrição feita por Winnicott, em 1965, e toma uma dimensão além de exclusivamente a manutenção da vida biológica do bebê. Trata-se de considerar também a produçáo de uma relação de afeto que parte de um adulto, dirigida a um bebê. A funçáo materna esta na condição de um "Outro Primordial” (PAIM; KRUEL, 2012) que, além dos cuidados, investe também afetivamente no bebê. Por uma questáo cultural e histórica, o termo é associado à mãe, daí o nome função materna.

$\mathrm{Na}$ mesma lógica cultural, o conceito "função paterna" está dirigido à condição de uma função simbólica denominada como "Nome-do-Pai". Uma metáfora para marcar o registro de que o bebê não é tudo e todo para a mãe. A função paterna coloca a mãe na condição de compreender que o bebê é também do pai e é um sujeito a instalar-se na cultura (PAIM; KRUEL, 2012); por isso não é passivo, terá algo a dizer e a fazer sobre o investimento do ambiente para transformá-lo.

Considerando-se as atuais estruturas familiares, é importante destacar que estas funções poderão estar presentes em um mesmo agente. Por isso, o termo "Função" é tão importante: é possível assumir as duas funções, independentemente da condição de gênero. Porém, para que isso ocorra, é necessário que este agente tenha também passado por seu próprio processo de inserção à cultura. 
Então, o nascimento de um bebê coloca em pauta, para uma mulher e um homem, sua própria condição de exercer sua função materna e sua função paterna, as quais, por vezes também estão abaladas pelos diagnósticos e prognósticos de risco de vida do bebê (pela prematuridade e outras patologias), e de transtornos ao seu desenvolvimento. $\mathrm{O}$ tratamento em IP precisa supor um caminho clínico (BORTAGARAI; PERUZZOLO; SOUZA, 2015), que considere os fazeres parentais como campo de construção de uma nova forma de investimento, tanto afetivo quanto de cuidado (LIMA; OKUMA; PASTORE, 2013), no filho com algum prognóstico.

Porém, o tratamento em IP precisa, também, identificar no bebê a forma singular de o mesmo reagir aos investimentos ambientais, considerando seus recursos instrumentais, entre os quais sua condição psicomotora.

Apesar de a psicomotricidade ter tido sua origem nos conceitos neuromotores, autores, como Henri Wallon (2007), em 1925, e Julian de Ajuriaguerra (1976), conseguiram deslocá-la para estudos também no campo da Psicologia, considerando os efeitos emocionais, afetivos e do meio ambiente sobre o movimento humano. Com isso, passou também a ser útil para o tratamento de afecçóes motoras em que se consideravam as influências do ambiente, da cultura, das relaçóes afetivas e emocionais.

Neste sentido, os conceitos de Esquema Corporal (EC) e Imagem Corporal (IC) foram sendo tratados teoricamente como campos do desenvolvimento humano e também do anúncio de que algo psíquico interfere nas habilidades motoras, nos movimentos, na postura e na relação do sujeito com o mundo, segundo Dolto (2012), em 1984, a ponto de produzir atrasos ou sintomas psicomotores (LEVIN, 2011).

Com a produção de um campo terapêutico a partir das teorias psicomotoras interpretadas por aportes psicanalíticos, deslocou-se o foco do transtorno psicomotor exclusivamente para focar-se na estrutura dos transtornos (LEVIN, 2011).

Para seguir nesta discussão, é preciso retomar três conceitos clássicos no campo da psicomotricidade: Esquema Corporal (EC); Imagem Corporal (IC), e Diálogo Tônico, e recolocá-los de forma que possam ser interpretados à luz não das aquisiçôes cronológicas para o desenvolvimento, mas sim como conceitos que instrumentalizam e dão significado aos investimentos relacionais entre os sujeitos.

O conceito de EC foi apresentado em estudos clássicos, como de Le Boulch (1984), como um modelo postural atribuído ao humano e, por algum tempo, foi interpretado como a imagem mental que o sujeito tem sobre si. O EC dá conta do reconhecimento de um organismo: o corpo. Isso provém de informaçôes proprioceptivas, interoceptivas e exteroceptivas, e em uma ordem evolutiva, à medida que este vai crescendo e se desenvolvendo (LE BOULCH, 1984).

Já a IC passa a representar o que de mental e social está em questão na construçáo do reconhecimento humano sobre si e sobre o mundo. Quando a psique foi considerada capaz de influenciar a condição de desenvolvimento do corpo, introduzem à IC componentes relacionados ao ambiente, à cultura, à história individual do sujeito, com isso, às relaçóes afetivas com outros humanos (LE BOULCH, 1984).

Françoise Dolto (2012), debruçando-se sobre a análise de crianças, definiu que o EC se estrutura pela aprendizagem e pela experiência, abstraídas pelas vivências do indivíduo, ao passo que a IC estrutura-se pela comunicação entre sujeitos desejantes, em uma vertente simbólica, inconsciente.

Apesar de esses dois conceitos serem apresentados separadamente, este estudo compreende como imbricados, à medida que um transforma o outro e que os dois constituem um sujeito. E, ainda, porque, para o bebê, estes dois campos ainda não estáo distintos.

Nesta perspectiva, se o EC é tomado como a "realidade de fato" (DOLTO, 2012, p. 10), as experiências no convívio com o mundo dependem da integridade deste organismo corpo. Corpos lesados por questóes neurológicas, musculares ou ósseas podem provocar perturbaçóes na construção de experiências e dificultar o processo de desenvolvimento do sujeito. Isso poderia implicar em uma construção de IC também prejudicada, mas que se instaura considerando-se os efeitos na construção das relaçóes construídas com os pais e com o social.

Destas relaçôes, apresenta-se o terceiro importante conceito para este estudo: o Diálogo Tônico. Apresentado por Wallon (2007), em 1925, como "diálogo-tônico-emocional", refere-se ao significado que os pais atribuem ao movimento do bebê, e à passagem desse ato motor neuronal para gesto intencional pelo bebê, potencializado nesse estudo como um ato dialético entre eles, porque os transforma a cada nova interpelação. Ou seja, é possível tomar e transformar o corpo reflexo em corpo diálogo, na forma de um diálogo tônico. Levin (2011) considera que o diálogo tônico está na condição de um discurso a ser decodificado. A questáo é que, quando o discurso toma o corpo do bebê, ele opera a partir das experiências e expectativas produzidas das funçóes maternas e paternas, então o que tem a dizer? Considerando-se os conceitos psicomotores, 
o diálogo tônico tem a dizer de um funcionamento psicomotor único, singular, exclusivamente produzido nessa dialética entre o bebê e seus recursos, seus pais e seus desejos.

Então, um caminho para a clínica, na condição de um sujeito em constituição, seria lançar uma Hipótese sobre o Funcionamento Psicomotor, supondo que, deste lugar, haveria espaço para que bebê-mãe-pai tenham algo a dizer, na condição de um diálogo tônico já no primeiro ano de vida do bebê.

\section{Estudo da Composição Teórica da Hipótese de Funcionamento Psicomotor}

Este estudo se propõe a olhar para o bebê em constituição, cujo desenvolvimento psicomotor é tomado como uma associação de gestos a serem construídos a partir da articulação com outros humanos, considerados como um "Outro Primordial" (JERUSALINSKY, 1983), porque interpretam o movimento motor do bebê e lhe atribuem sentido.

Essa interpretação é produzida a partir dos significantes maternos e paternos, ou seja, os primeiros conceitos relativos às sensaçóes vividas pelo bebê sobre si e sobre o mundo são oriundos de seus cuidadores. É sob essas experiências que o bebê produz seus próprios significantes, sua "matriz simbólica" (LEVIN, 2011).

Isso acontece porque o corpo passa a ser marcado pelo toque, anunciado pela fala, desejado também pelo olhar, a partir das interpretaçōes do funcionamento do bebê, feitas pelos pais. O movimento se transforma em gesto tanto quanto e enquanto haja um Outro Primordial, que capte, neste movimento, uma significação (LEVIN, 2011).

É possível então que o terapeuta faça uma leitura náo mais do funcionamento motor, mas do funcionamento psicomotor: no diálogo tônico, no discurso entre o bebê, mãe e pai, que pode se dar pelo fazer do corpo (BERGÈS, 2005).

Neste sentido, é importante compreender que este gesto do bebê pode ser tomado como um movimento de dar-se a ver para o Outro e pelo Outro. O bebê responde ao que ele supóe que seus pais esperam dele. Essa imagem, produzida pelo bebê sobre si, porém na relação construída com o Outro, é o campo do conceito psicomotor da IC. É no campo do investimento primordial do Outro que a IC do bebê se constitui e é na articulação com os elementos do EC que ela se manifesta. Este é o lugar que a Hipótese de Funcionamento Psicomotor poderá ser elaborada para contribuir no tratamento do bebê cujo corpo obstaculiza o desenvolvimento.

Levin (2011) refere existir uma informação visível e uma invisível no movimento e no gesto da criança. $O$ visível seria os obstáculos reais $(\mathrm{EC})$ que o bebê possui sob a perspectiva psicomotora, como uma apraxia, uma hiperatividade, por exemplo. Já o invisível seria anunciado neste campo psicomotor pelo gesto (IC), porém construído pelas sensaçôes afetivas produzidas entre o bebê e seus pais, relativizadas pelo náo funcionamento adequado do motor e psicomotor, como, por exemplo, os sintomas de recusa de contato do bebê (MURATORI, 2014).

Por isso, não se trataria de realizar um diagnóstico somente sobre o que está atrasado ou em desajuste das aquisiçóes motoras ou psicomotoras do ponto de vista cronológico do bebê, e sim como algo inusitado que está constituindo o bebê. Diz de sua relação discursiva com os pais e de sua condição instrumental para tal.

O invisível seria o inusitado, o que não é avaliado como um marco do desenvolvimento, mas sim uma manifestação afetiva do bebê, elaborada no corpo, a partir das representaçóes parentais, denominadas por Levin (2011) como "cadeia significante". Ou seja, os pais lançam mão de suas experiências pessoais, seus desejos pela maternidade e paternidade, suas expectativas de futuro para o bebê e atribuem sentido (conteúdo simbólico) aos movimentos motores do bebê, transformando-os em gestos. Estes gestos, por sua vez, depois de registrados pelo bebê, passam a compor seu repertório de diálogo-tônico com seus pais.

Esta teoria ajuda a pensar como o bebê se apropria do conhecimento de seu corpo (EC). E, ainda, como este corpo está sendo simbolizado, representado (IC), e o que as funções parentais estão oferecendo de conteúdo simbólico para que o bebê tenha, em seu repertório, possibilidades de ampliar sua cadeia de significantes para colocar-se no lugar de filho.

Porém, a forma como o bebê se coloca a dar-se a ver pelo e para o Outro, seu gesto, poderá anunciar quais os recursos de seu repertório estrutural e instrumental (o visível, o EC) estão disponíveis ou não são acessados por alguma deficiência de funcionamento.

É este lugar do gesto que coloca crianças com os mesmos diagnósticos motores e, por vezes, psicomotores, a apresentarem sintomas diferentes. Para a clínica com bebês, apesar de ser muito cedo para se tratar de um sintoma, ainda assim, o que o bebê faz com sua condição motora, advinda do quadro patogênico, também é influenciado por 
uma cadeia de significantes familiares. É isso que vai produzir o inusitado no bebê: seu gesto singular.

E, para a criança sem questóes neurológicas e que produz um gesto singular que angustia os pais, como uma torpeza, um atraso nas aquisiçóes posturais, uma inibição, uma agitação, sob a ótica desse estudo, também é um anúncio deste encontro entre o corpo do bebê e o discurso dos pais.

É comum que o terapeuta ocupacional receba casos de crianças entre um e dois anos de idade com a queixa, tanto familiar quanto de outros terapeutas, de que não caminha e não se sabe o motivo. O motivo não está no motor, no tônus, no funcionamento neurológico de base, mas está no que vai significar para esta criança apropriar-se deste. Para a psicomotricidade, o que se propóe a discutir é "[...] a posição que ocupa este corpo no mito familiar" (LEVIN, 2011, p. 157). E para a IP, sob a ótica da terapia ocupacional, o que se propóe é discutir a posição de "fazer-se filho a partir do gesto como anúncio de seus recursos e de sua interpretação sobre como os adultos estáo fazendo-se pais".

Para que esta cadeia de significantes seja desvendada, desloca-se o olhar do corpo e mira-se na história de como o filho está sendo desejado pelos pais e como o bebê está compreendendo sua história na posição também de sujeito desejante.

Quando há uma patologia, trata-se de perceber que caminhos conscientes e inconscientes tanto a função materna (que sustenta a vida biológica e psíquica do filho) quanto a função paterna (que coloca o filho na condição de um sujeito inserido em uma cultura) estâo agindo no desenvolvimento do bebê.

Para o terapeuta em IP, a interpretaçáo do encontro entre as possibilidades reais do aparato instrumental do bebê (EC) e o que os pais estão significando disso (o simbólico), ou seja, do diálogo-tônico entre a tríade (IC), poderia produzir uma Hipótese de Funcionamento Psicomotor, que contribuiria para a construção do plano de tratamento.

Atualmente, algumas áreas instrumentais vêm reunindo saberes específicos, como o funcionamento de linguagem (SURREAUX, 2006; CRESTANI; MORAES; SOUZA, 2015; VENDRUSCOLO et al., 2012) e a própria psicomotricidade (PERUZZOLO et al., 2015), aos resultados de protocolos de avaliaçáo, formulando novas hipóteses de interpretaçóes sobre o bebê em constituição, já no primeiro ano de vida.

Este estudo segue a mesma direçáo, propondo que náo se incorra no erro de tomar o corpo do bebê ou o discurso dos pais isoladamente como o lugar do tratamento. Defende-se que este período da vida seja compreendido como em estruturaçáo na relação entre o aparato biológico, mas também com o conteúdo simbólico e cultural posto à sua disposição. Portanto, seria possível tomar um transtorno motor e/ou psicomotor como um sintoma e considerá-lo a partir de uma Hipótese de Funcionamento Psicomotor, por meio da qual o terapeuta pudesse compreender este gesto como único e singular. Um anúncio em uma cadeia significante que ainda está estruturando-se e que, então, poderá ser remetido à condição de um gesto significativo.

Trata-se da defesa de que é possível tomar o irregular do psicomotor da criança em constituição (primeiros anos de vida) e, considerando as condiçôes familiares, deslocá-lo para a forma de um gesto. É importante ressaltar que este gesto é único para cada bebê e seus pais, pois surge das experiências e do desejo de cada um destes em assumirem seus papéis familiares.

No entanto, convém diferenciar a situação em que há sinais claros de lesão cerebral, como nas encefalopatias motoras não progressivas, em que já há evidências de sintomas motores no segundo semestre de vida, pela permanência de reflexos arcaicos, da falta de evolução da motricidade voluntária, por exemplo. É um corpo que, no sintoma, pesa duplamente: em primeiro lugar, porque é a criança que tem que se a ver com ele em movimento e, segundo lugar, porque este movimento não é agradável aos olhos do Outro Primordial.

Porém, o fato de existirem sintomas patogênicos não exime o terapeuta de ir à busca da compreensão sobre o que do gesto do bebê seria possível para constituir-se sujeito em sua função de filho, além de suas impossibilidades.

Já nos casos de risco de evolução para autismo, é possível que os sinais de assimetria corporal e flaping, descritos por Muratori (2014), que também aparecem nas pesquisas de Esposito e Venuti (2009), ou mesmo as dificuldades de domínios de matrizes corporais postulados por Bullinger (2006), sejam tomados como sintomas transitórios, porque anunciam um sofrimento, uma impossibilidade, mesmo que ainda não haja um diagnóstico fechado.

Portanto, para a produção de uma Hipótese de Funcionamento Psicomotor, supóe-se que o gesto psicomotor pode ser tomado como condição transitória, no percurso do amadurecimento neuronal e na ampliação das experiências instrumentais. Anuncia como o bebê e a função materna estáo estabelecendo uma relação corporal, na qual há um sistema semiótico também corporal em curso. Há espaço para romper com o irregular como patológico e tomá-lo como anúncio da forma como 
o sujeito está se apropriando do gesto na troca com o outro (SURREAUX, 2006).

Nesta perspectiva, a concepção de que, para o bebê pequeno, os conceitos de EC e IC, juntamente com seus aspectos estruturais e instrumentais, estão imbricados, influenciando a constituiçáo um do outro, propóe não ser mais possível supor um tratamento baseado na reabilitação da função, pois o que não funciona é anunciado somente a partir do transtorno instrumental, nos conceitos de EC. O tônus, o equilíbrio, a lateralidade e a dominância, a motricidade ampla e fina, o ritmo e a temporalidade, e a inabilidade instrumental, se atrasados ou definitivamente inábeis pela patologia, se tomados como tal pelo terapeuta e tratados a partir de técnicas que reabilitam a função mecanicamente, não alcançarão a magnitude do que se compreende como sujeito em constituição. Ficariam fora da cena terapêutica tanto a origem de um sintoma, quanto os efeitos causados por uma patologia sobre as funçóes materna e paterna.

É possível supor que a constituição da atividade psicomotora de um sujeito psicomotor se dá na imbricação entre EC e IC: entre o bebê e um adulto, na constituição de um filho e de uma mãe e de um pai, nos atos corporais, na sua gestualidade, seu diálogo tônico.

É importante considerar, na clínica em IP, como a mãe compreende-se na função de mãe e o que ela espera da função do filho, pois a condição instrumental do bebê poderá influenciar esta construção dos papéis familiares. O que acontece entre a mãe e o bebê, pela via da relação corporal, pode ser decifrado a partir de como a dupla constrói seus diálogos tônicos.

A forma como o corpo do bebê faz (de fazer-se filho dessa mãe) diz da interpretação ou da influência que a função materna lhe atribui. Neste sentido, há uma interpretação sobre o inconsciente materno; porém, onde, para a psicanálise, por exemplo, estaria a escuta, para a psicomotricidade, à luz da terapia ocupacional (LEVIN, 2011; LIMA; OKUMA; PASTORE, 2013), está o olhar sobre o fazer-se bebê e o fazer-se mãe.

Isso coloca cada tratamento clínico como único, pois, para cada bebê, seria produzida uma condiçáo psicomotora pautada pelo investimento da função materna e pela condiçấo do bebê de colocar-se na cena, também única. O bebê seria o que sua mãe lhe anunciaria que desejaria que fosse, mas que, por sua vez, ela estaria também alimentada pelo que o bebê poderia ou náo fazer com seu aparato instrumental. Esta afirmação determina a singularidade de cada bebê e, mais especificadamente, cada bebê e sua mãe, em tratamento.

Para a psicomotricidade, poder-se-ia supor que é no campo da IC que se sustentará o desenvolvimento do bebê para a condição de filho. É na singularidade do desejo materno do encontro com seu bebê e do potencial deste para responder que se produzirá a condição psicomotora para o desenvolvimento.

Então, o funcionamento psicomotor do bebê anuncia também o investimento relacional com sua mãe. Daí a possibilidade de, em tratamento, poder atribuir-se uma Hipótese de Funcionamento Psicomotor como anúncio do encontro entre a função do filho, a função de mãe e de pai, e também entre o EC e a IC, respectivamente. Somente, então, após esse processo, é possível pensar um caminho clínico para o tratamento de bebês em IP.

O que a experiência clínica tem demonstrado é que as produçôes do bebê na cena terapêutica, interpretadas pelo terapeuta, poderão deslocar a elaboração da funçáo materna e, por consequência, também a função do filho. O irregular do psicomotor, que não dá suporte à mãe para reconhecê-lo como filho, é tomado no tratamento, para que se transforme em gesto, para que tenha algo a dizer de uma filiação.

Esta é a tarefa da IP, que acontecerá tanto pela identificação do potencial psicomotor do bebê e pela facilitação instrumental de seu desenvolvimento quanto pelo entendimento que isso não se dará sem que seja inserido na ordem de um gesto endereçado a alguém, de preferência os pais. Um bebê sentará, andará, pegará, porque alguém exerce as funções parentais e espera isso dele. Portanto, não há como aplicar exercícios a um bebê, é preciso pensar em um corpo em relação, no caso com aquele que exerce a função materna e paterna.

Este estudo amplia a discussão e defende um caminho para o tratamento de bebês que considere seu aparato instrumental, mas também seus aspectos estruturais, sua construção em um diálogo tônico, tanto de EC quanto de IC, na relação armada com seus pais.

Para lidar com todas essas questôes, é preciso considerar a afirmação de Surreaux (2006) de que o caminho terapêutico não deve lidar com a ideia da supressão urgente do irregular identificado através do sintoma. Para que o sintoma psicomotor desapareça, é preciso intervir no que o provoca e não no que ele é. Levin (2011) afirma que o sintoma psicomotor é um dar-se a ver. É um pedido de ajuda para compreender algo que angustia, que não está bem compreendido pelo bebê. Considerando-se que é no fazer que se instaura o encontro entre o 
sujeito singular, a sua cultura e a sua história, em um contexto social (LIMA; OKUMA; PASTORE, 2013), é preciso tomar o sintoma psicomotor como a condição de uma criança de fazer-ser nos encontros e desencontros entre ela e seus pais.

O tratamento a partir de uma Hipótese de Funcionamento Psicomotor implica oferecer à criança um novo fazer psicomotor que produza um novo encontro entre ela e seus pais, para, daí ser a partir deles, que já são outros.

\section{Conclusão}

Os referenciais teóricos trazidos para este estudo propóem um caminho clínico estruturado em conceitos clássicos psicomotores, pautados por referenciais psicanalíticos e terapêutico ocupacional. Este encontro vem das pesquisas que investem na busca da identificação da origem cada vez mais cedo de sinais ou sintomas de atraso no desenvolvimento e na constituição psíquica do bebê, na proposição de uma IP a partir de referenciais psicomotores e no deslocamento desses referenciais para pensar a clínica com bebê e sua singularidade, pois se trata de um sujeito em constituição.

Certamente, outros caminhos existem e novos surgirão problematizando e encontrando recursos para o tratamento do bebê. Porém, quando um terapeuta estiver disposto a considerar que o sintoma psicomotor de um bebê está anunciando sua condição de interpretação sobre si, sobre os pais e sobre o mundo, e que, para ajudá-lo a reencontrar-se e ao outro, considerando uma intervenção psicomotora, há um bom caminho clínico, quando se produz uma Hipótese de Funcionamento Psicomotor.

\section{Referências}

AJURIAGUERRA, J. Manual de psiquiatria infantil. Rio de Janeiro: Masson do Brasil, 1976.

ARAÚJO, A. C.; LOTUFO NETO, F. A nova classificação americana para transtornos mentais: o DSM-5. Revista Brasileira de Terapia Comportamental e Cognitiva, São Paulo, v. 16, n. 1, p. 67-82, 2014. Disponível em: <http://www.psicomotricidade.com.br/index.htm>. Acesso em: 8 abr. 2013.

BERGÈS, J. O corpo na Neurologia e na Psicanálise: lições clínicas de um psicanalista de crianças. Porto Alegre: Èditions Érès, 2005.

BORTAGARAI, F.; PERUZZOLO, D. L.; SOUZA, A. P. R. A interconsulta como dispositivo interdisciplinar em um grupo de intervençáo precoce. Distúrbios da Comunicação, São Paulo, v. 27, n. 2, p. 392-400, 2015.
BULLINGER, A. Approche sensorimotrice des troubles envahissants du dévelppment. Contrastes, Paris, v. 2, n. 25, p. 125-139, 2006.

CRESPIN, G.; PARLATO-OLIVEIRA, E. Projeto Préaut. In: JERUSALINSKY, A. Dossiê autismo. São Paulo: Instituto Langage, 2015. p. 436-455.

CRESTANI, A. H. et al. A experiência da maternidade e a dialogia mãe-filho com distúrbio de linguagem. Revista CEFAC, São Paulo, v. 14, n. 2, p. 350-360, 2012.

CRESTANI, A. H.; MORAES, A. B.; SOUZA, A. P. R. Análise da associação entre índices de risco ao processo de desenvolvimento infantil e produçáo inicial de fala entre 13 e 16 meses. Revista CEFAC, Sáo Paulo, v. 17, n. 1, p. 169-176, 2015.

DOLTO, F. A imagem inconsciente do corpo. São Paulo: Perspectiva, 2012.

DUAN, Y. et al. Prognosis of psychomotor and mental development in premature infants by early cranial ultrasound. Italian Journal of Pediatrics, London, v. 41, p. 1-7, 2015. PMid:25886733.

EICKMANN, S. H.; MALKES, N. F. A.; LIMA, M. C. Psychomotor development of preterm infants aged 6 to 12 months. São Paulo Medical Journal, São Paulo, v. 130, n. 5, p. 299-306, 2012. http://dx.doi.org/10.1590/ S1516-31802012000500006.

ESPOSITO, G.; VENUTI, P. Symmetry in infancy: analysis of motor development in autism spectrum disorders. Journal Symmetry, Switzerland, v. 1, n. 2, p. 215225, 2009. http://dx.doi.org/10.3390/sym1020215.

JERUSALINSKY, A. Función materna y estimulación temprana. Cuadernos Del Desarrollo Infantil, Buenos Aires, n. 2, p. 71-77, 1983.

KUPFER, M. C. et al. Predictive value of clinical risk indicators in child development: final results of a study based on psychoanalytic theory. Revista Latinoamericana de Psicopatologia Fundamental, São Paulo, v. 13, n. 1, p. 31-52, 2010

LE BOULCH, J. O processo de desenvolvimento psicomotor do nascimento até 6 anos. Porto Alegre: Artes Médicas, 1984.

LEVIN, E. A clinica psicomotora: o corpo na linguagem. Petrópolis: Vozes, 2011.

LIMA, E. M. F. A.; OKUMA, D. G.; PASTORE, M. N. Atividade, ação, fazer e ocupação: a discussão dos termos na terapia ocupacional brasileira. Cadernos de Terapia Ocupacional da UFSCar, São Carlos, v. 21, n. 2, p. 243254, 2013. http://dx.doi.org/10.4322/cto.2013.026.

MAGGI, E. F. et al. Crianças pré-termo apresentam desempenho motor, cognitivo e funcional desfavorável em relaçáo a neonatos a termo em idade pré-escolar. Jornal de Pediatria, Rio de Janeiro, v. 90, n. 4, p. 377-383, 2014. http://dx.doi.org/10.1016/j.jped.2013.10.005. 
MURATORI, F. O diagnóstico precoce do autismo: guia prático para pediatras. Salvador: Núcleo Interdisciplinar de Intervenção Precoce da Bahia, 2014.

PAIM, F. F.; KRUEL, C. S. Interlocução entre psicanálise e fisioterapia: conceito de corpo, imagem corporal e esquema corporal. Psicologia: Ciência e Profissão, Brasília, v. 32, n. 1, p. 158-173, 2012.

PERUZZOLO, D. L. et al. Participação da terapia ocupacional na equipe do Programa de Seguimentos de Prematuros Egressos de UTIN's. Cadernos de Terapia Ocupacional da UFSCar, São Carlos, v. 22, n. 1, p. 151161, 2014.

PERUZZOLO, D. L. et al. Contribuições à clínica da terapia ocupacional na área da intervenção precoce em equipe interdisciplinar. Cadernos de Terapia Ocupacional da UFSCar, São Carlos, v. 23, n. 2, p. 295-303, 2015.

SASSA, A. H. et al. Bebê de risco: acompanhando o crescimento infantil no primeiro ano de vida. Acta Paulista de Enfermagem, São Paulo, v. 24, n. 4, p. 541-549, 2011. http://dx.doi.org/10.1590/S0103-21002011000400015.
SIQUEIRA, M. B. C.; DIAS, M. A. B. A percepção materna sobre vivência e aprendizado de cuidado de um bebê prematuro. Revista Epidemiologia e Serviços de Saúde, Brasília, v. 20, n. 1, p. 27-36, 2011. http://dx.doi. org/10.5123/S1679-49742011000100004.

SURREAUX, L. Linguagem, sintoma e clinica em clinica de linguagem. 2006. 202 f. Tese (Doutorado em Letras) - Universidade Federal do Rio Grande do Sul, Porto Alegre, 2006.

VENDRUSCOLO, J. V. et al. A relação entre o aleitamento, transição alimentar e os indicadores de risco para o processo de desenvolvimento infantil. Distúrbios da Comunicação, São Paulo, v. 24, n. 1, p. 41-52, 2012.

VIEIRA, M. E. B.; LINHARES, M. B. M. Desenvolvimento e qualidade de vida em crianças nascidas pré-termo em idades pré-escolar e escolar. Jornal de Pediatria, Porto Alegre, v. 87, n. 4, p. 281-291, 2011. http:// dx.doi.org/10.2223/JPED.2096.

WALlON, H. A evolução psicológica da criança. São Paulo: Martins Fontes, 2007.

\section{Contribuição dos Autores}

Dani Laura Peruzzolo: Concepção e redação do artigo. Ana Paula Ramos de Souza: Revisão do artigo. Todos os autores aprovaram a versão final do texto.

\section{Fonte de Financiamento}

$\mathrm{CNPq}$ - bolsa de Produtividade em Pesquisa do último autor.

\section{Notas}

${ }^{1}$ O artigo é parte da tese apresentada ao Curso de Doutorado de Programa de Pós-graduação em Distúrbios da Comunicação Humana, da Universidade Federal de Santa Maria (UFMS, RS). 